\title{
EXPERIENTIAL LEARNING THEORY AND TRADITIONAL CRAFTSMANSHIP - THE OBJECT-THEME RELATIONSHIP
}

\author{
Jonathan Yonghui LEONG ${ }^{1 *}$, Chee-Han LIM² \\ ${ }^{1}$ Dr., Singapore University of Social Sciences (SUSS), SINGAPORE, \\ jonathanleongyh@suss.edu.sg \\ ${ }^{2}$ Dr., Singapore University of Social Sciences (SUSS), SINGAPORE, chlim@suss.edu.sg \\ ${ }^{*}$ Corresponding Author
}

\begin{abstract}
The Experiential Learning Cycle Theory (ELCT) formulated by David Kolb is the thread that weaves together the divergent approaches taken by experiential educators and practitioners. It has, by virtue of its status in the discipline, also received its fair share of criticism, from its overly-discrete separation of the four stages of learning to assuming that learning results from adaptive choices and not the other way round. In our attempts at implementing it, what we found lacking in Kolb's formulation was in the disappointing student performances in the four stages of the ELC. We observed how students describe experiences disconnected from the learning outcomes, exhibit fleeting emotions triggered by novelties encountered in the field, and struggle to explain how the skills acquired could possibly be applied in other situations. Students perform as if they have spent an entire course learning how to swing a bat - without knowing that they were supposed to be hitting a ball, scoring points, and winning the game. In short, students had no idea what they were supposed to experience, observe, conceptualise, experiment with, and the larger ends for doing so.
\end{abstract}

If experiential learning is the "most natural way to learn", it pays to heed how humans across epochs and cultures have always naturally learned. In our search for a practical way to ensure that courses under our charge remain faithful to Kolb et als work yet transformative for their recipients, we found inspiration from anthropological research into craftsmanship. This paper presents a framework for course design that seeks to make the ELCT much more workable within institutional settings, through integrating central characteristics of traditional craft apprenticeship with that of the ELCT. From the study of ethnographies of traditional crafts, we identified their four key components, namely, the "object", "objective", "skill" and "theme" present in every craft. These four components - and the relationships between them - provide the "what" and the "why" towards which the four actions found in the ELCT are directed. In so doing, we not only inject substance into the formal nature of the ELCT stages, anchor traditionally abstract academic content in practice, but also resurrect a pedagogical method that has survived natural (and cultural) selection.

In the following sections, we will first compare the ELCT with the didactic approach as a means of highlighting the core strengths of the former, and the challenges we met while trying to implement it in its ideal form. This would be followed by a discussion of the four key components of craft apprenticeship, how we synthesize them with classical ELCT to create a new experiential learning framework, and finally, comparisons of students' performance before and after its implementation.

Keywords: Experiential Learning, Pedagogy, Heuristic Learning, Skills Portability

\section{EXPERIENTIAL LEARNING VS DIDACTIC TEACHING}

The didactic approach is teacher-centred (Entwistle, 1997) and typically comprises a lecture through which information specific to the discipline is transmitted from teacher to student. This compromises the cultivation of students' ability at establishing and uncovering the relationships between facts and skills (Marton \& Saljo, 1997). Didaticism, while common due to the "economical means of transmitting factual information to a large 
audience", shows "no guarantee that effective learning will result" (Walkin, 2000), and has been found to have an "undesirable impact on motivation of students" (Gow \& Kember, 1993), and can "reduce students' interest in learning" (Newstead \& Hoskins, 2003). Conversely, studies show that experiential methodologies not only meet the needs of adult learners, but also results in deeper understanding and application of the concepts, and creates a more rewarding learning environment (Kolb \& Kolb, 2006; Spencer \& Jordan, 1999; Yballe \& O'Conner, 2000). This is not only due to the learner-centric nature of experiential learning that leads students to construct knowledge on their own, but also a focus on the dialectic relationships between learners and their environments and between the four stages of the ELC (Passarelli \& Kolb, 2012). Such methodologies have been studied for their potential in earlier stages of education, e.g., the International Baccalaureate Diploma Programme (Hayden, 2018), are shown to have a positive effect for students in acquiring skills deemed critical to a wide variety of careers (Bradberry, 2018), and even benefits stretching to those in executive leader roles (Loveless, 2021). Experiential learning methodologies have, as such, been found to be beneficial for various life-stages of learners, and as a pedagogy with great potential.

Experiential learning has been summarised by Kolb $(1976,2015)$ as a cycle with four stages, namely:

1. Concrete experience, during which learners, while performing a task, encounter a phenomenon in a manner unmediated by conventional representations like texts, pictures, audio and video recordings.

2. Reflective observation, during which learners deliberate over what they have witnessed in themselves, their actions, consequences of their actions, others' behaviours, etc.

3. Abstract conceptualization, during which learners attempt to form a theory/model of what is being (or is to be) observed.

4. Active experimentation, during which learners attempt to verify hypotheses conceptualised from stage three, with the objective of improving its validity. In the process, the learner may possibly plan for a new experience which leads to further observation, conceptualisation, and then experimentation, thereby repeating the cycle.

\section{IMPLEMENTING CLASSICAL ELCT}

The above summary of the four stages of the ELCT may be an over-simplification of Kolb's extensive (and at times philosophical) writings about the subject, but they suffice in showing that the ELCT does not provide much guidance to students on what they should be experiencing, observing, conceptualising, and experimenting with, or the purposes of doing so. This lack of prescriptions may be a virtue for mature learners who have the luxury of spending years in the field soaking up the social mores, tricks of the trades, principles, etc. but for young students taking university courses that typically do not run for more than 12 weeks, it can create much confusion and duress.

Indeed, in our observations of overseas study mission courses run by others, and our early applications of the ELCT in ours, we noticed the following challenges that students face in the corresponding stages of the cycle:

1. Concrete experience: students try to experience everything during field trips, often ending up paying attention to fascinating sights and sounds that have little to do with the course content.

2. Reflective observation: students could not help but notice attention-grabbing phenomena, and reflecting on fleeting responses to the glitz.

3. Abstract conceptualization: unable to relate their experiences and observations to larger issues, students regurgitate examples provided in the course material.

4. Active experimentation: students did not create anything novel to experiment with, and hence had to utilise hypotheses that they read elsewhere.

It appears that the ELCT's greatest strength, in encouraging students to generate knowledge and take charge of their own education, is also its Achilles' heel for courses that adhere to academic schedules found in modern university settings. What students require, we discovered, is not more intervention from instructors because, as they demonstrated in stages three and four, are apt to regurgitate whatever examples and interpretations that instructors provide. What is needed is a "beefed up" version of the ELCT that strikes a balance between acting as a learning scaffold and allowing room for self-directed explorations; it should not only serve as guidelines for course design and structuring learning processes, but also a heuristic device with which students manage their own experiential learning journeys. The "meat" that we were looking for, was serendipitously found from burying ourselves in ethnographies of traditional craft apprenticeship. 


\section{ANTHROPOLOGY OF CRAFTSMANSHIP}

If we were to assume that human behaviours found across cultures that had survived thousands of years of social change must have fulfilled functions critical to the survival of our species, then we should certainly pay attention to the apprenticeship mode of learning. Even though ethnographies of traditional crafts were a mainstay of anthropology (e.g., Goody, 1982; Dilley, 1989), the researchers were more interested in traditional anthropological topics like social relations, rituals, household structures, etc. than in the process of acquiring craftmanship. It was Jean Lave and Etienne Wenger who first cast light onto the "learning" dimensions of crafts (Lave \& Wenger, 1991), i.e., "apprenticeship", popularising now-familiar terms like "communities of practice", "legitimate peripheral participation", and most of all "situated learning". Many ethnographies of the kind followed, importing these concepts to make sense of modern forms of apprenticeships (e.g., Field \& Dubhchair, 2001; Fuller and Unwin, 2001).

Lave and Wenger's concepts are indeed useful for making sense of apprenticeship across cultures and ages, but we also began to notice that embedded within the thick descriptions are certain features of craftsmanship that kept appearing across the accounts. We surmise then, that instead of coming up with experimental new ways of teaching youngsters, why not utilise some ready-to-go tried and tested features that could potentially perform very well in experiential learning courses?

In Lave \& Wenger's accounts, the acquisition of craftsmanship involves a novice engaging in "legitimate peripheral participation" under the tutelage of a master often with other apprentices of various seniorities and expertise, and progressing from the peripheries of the "community of practice" towards the axis, eventually graduating to become a practitioner with her or his own business. Amongst the myriad crafts documented across continents, one could also find commonalities like the use of physical punishment, avoiding learning under parents, and the predominance of male apprentices (Lancy, 2012). What caught our attention were four key components of crafts, yet to be documented, that captures implicit ways in which every craft is internally organised.

These four components are what we call the "object", "objective", "skill", and "theme" present in every craft described in ethnographies we have come across. The first three are found in crafts themselves, while the fourth in the learning process:

- The object of a craft refers to the "thing" to be analysed and transformed

- The objective of a craft refers to the desired outcomes from analysing and transform the object

The skills of a craft refer to the acts or tools required to analyse and transform the object to reach the objective

To further summarise the above, skills or tools are employed to analyse and transform an object unique to a craft, for the purpose of achieving a pre-defined objective. To give an example, in traditional carpentry, skills like hammering, chiselling, fingering textures, and tools like saws and rulers are employed to make sense of its object, wood, and achieve the objective of transforming it into furniture.

The themes of a craft enter the picture in the apprenticeship process. They are often coded as tales or metaphors, expressed as mnemonics or poetic utterances like songs or sayings, and refer to general principles that connect seemingly disparate parts of a craft for the purpose of "portability": the elevation of practitioners' skills to higher levels and broadening their skills beyond their areas of specialties.

To give an example of how themes work, in her ethnography on the mathematical "senses" amongst carpenters in Cape Town, South Africa, Millroy (1992: 104) reflects on a statement uttered by a master carpenter while apprentices were reckoning with measuring and carving squares, "There is a straight line where the sky meets the sea, at the horizon. It is the straight line that God gave us. You can see if you look at the tops of buildings when you are halfway up the mountain. If you check the tops of buildings, which are straight, you can line them up with your eye." This simple metaphor of straight lines illustrates how a theme functions to elevate and broaden an apprentice's skills at perceiving lines in nature, carving proportional designs, aligning parts of furniture to one another, fitting them to buildings, etc. across different types of wood, structures, and even massive natural phenomena.

\section{THE OBJECT-THEME PAIR}

In addition to our students' poor performance in the four stages of the ELCT, we also face insurmountable obstacles from our institution's curricular structure. The need for courses to be completed in weeks, the permitted assignment formats, the need to work with instructors from various disciplinary backgrounds, and the lack of follow-ups after a course ends, etc. make it impossible to employ the four stages in their ideal forms. 
The greatest impact is found in the lack of opportunities for students to exercise active experimentation, and the lack of time and space to separate the stages of concrete experience, reflective observation, and abstract conceptualisation in a discrete manner. Given that our overseas study mission courses are classified as standalone "electives" that do not constitute part of a students' major discipline, there are no subsequent courses that allow students to follow-up with experimenting with what they have conceived in our courses. The length of the field trip, typically five to seven days, also do not allow students time to progress comfortably from experience to observation to conceptualisation. In searching for a solution, we invented a simple "object-theme" pair of guiding concepts with which we design our courses, plan their itineraries, craft assignments, and socialise students into the ways of experiential learning through integrating the pair with a simplified version of the ELCT.

\subsection{The Object}

The design of courses begins with identifying a specific phenomenon that instructors dearly want students to learn about, and which is also readily observable in the destination city. This phenomenon is then conceptualised as a noun, e.g., "conservation practices in Jakarta", that serves as the object of the skills that are cultivated through the course. This step is critical because conventional university curricular tend to pay grave attention to "skills", often expressed as "learning outcomes", without much reference to their purposes, origins, or applications. A consequence of this overweight is that both instructors and students are so caughtup with measuring learning outcomes that hardly anyone pays attention to what those skills are supposed to be used on. One would only have to imagine having carpenters spend years studying carpentry without knowing that the craft's very raison d'etre is to transform wood into furniture, to also consider the absurdity of courses not containing any reference to its object and objective.

By having a pre-designated object looming over the horizon, we can ensure that the learning outcomes of the course represents skills that can effectively analyse and transform a specific "thing", instead of being mere formulae or theories to be eagerly forgotten by students once they graduate. Assignments can then be reverseengineered to test those very skills derived, ensuring that students are fairly evaluated on practical abilities rather than outstanding memories. Having a clearly-articulated object also helps course designers with planning itineraries. Instead of bringing students to museums and historical sites simply because they are "culturally significant", focusing on locations that allow students to encounter the object of the course could eradicate trips that may be central to a tourist's itinerary, but could very well be a waste of time for learning purposes.

The reference to an object in experiential learning courses also serves another purpose: to let students know what they are supposed to experience. In other words, in experiential learning courses, the object of skills is also the object of experience, just like how wood is to be hammered as it is to be encountered. As mentioned earlier, at the concrete experience stage, students often had no idea what they were supposed to experience during field trips. By articulating the objects of our courses prominently in the title of each course, we not only communicate to the students in an unequivocal fashion what they could expect to witness and gain competency over during the trip, it also ensures that they remain undistracted by irrelevant information, and focus their attentions on extracting the most utility from a very short journey. One could imagine students struggling to experience and observe everything during a five-day trip to the bustling city of Jakarta without a pre-designated object, compared to another that explicitly tells them to only pay attention to "conservation practices".

\subsection{The Theme}

The second step to course design is the conceptualisation of a theme that involves considerably more work. This is because course designers need to preserve the strengths of the experiential learning method by striking a balance between the portability and applicability of the skills they wish to cultivate amongst their students. One of the key strengths of the ELCT is precisely its egalitarian emphasis on both portability and applicability. Through the very process of learning from doing and observing how others do it, practical skills certainly feature greatly in the theory. Yet conceptualisation and experimentation also encourage students to constantly move between real-life practices, principles, and novel explorations so that what the skills they have acquired in the first two stages continue to deepen and broaden beyond what those skills were initially used for and on.

In striking such a balance, instructors need to understand that abstract theories essentially summarise and explain relationships between numerous phenomena in a general fashion, allowing students to port over what they know about one phenomenon to another readily. Students familiar with the theory of gravity could understand the trajectory of a falling apple as much as the orbiting of the Moon around the Earth. Despite this high level of portability, students have little to offer in their abilities to make use of gravitational forces to create useful products, such as how the ancient Chinese invented the trebuchet. Emphasizing sheer applicability of 
skills, found in technical education that teaches a narrow set of specialised techniques, e.g., maintenance of automobiles, comes at the expense of the students' ability to creatively adapt those skills to another object or another context; one could hardly trust a car mechanic to help with interior design. In short, having only an object in a course swings the skills towards narrow applicability, and having only a theme swings them in the opposite direction.

Because of their training in traditional academia, the majority of instructors have a natural tendency to lean towards the abstract. Henceforth, it is more practical to derive the theme from the object rather than the other way round. A good theme must fulfil two criteria. First, the object of the course must be a sub-object of the theme, and second, the theme must encompass other objects that the instructor wishes the students' skills to be applicable to as well. For instance, the object "conservation practices in Jakarta" could be paired with "economic development" because the latter is broader in scope than the former, and allows students to apply skills learned from interacting with the object on other objects like "poverty alleviation" similarly related to economic development.

\section{A WORKABLE EXPERIENTIAL LEARNING FRAMEWORK}

With the object-theme pair in place, we could then stack on the ELCT, simplified into two stages of "experience" and "reflection" as the prescribed actions to be administered on the pair. As mentioned earlier, the object serves as that of both skills and experience. We have combined experience and observation into a single experiential action, and hence in our implementation, students are required to experience the object and observe how practitioners do so as well. Depending on how abstract the theme is, instructors could also point students to its manifestation to be experienced and observed. For instance, "economic development" could be perceived via a city's transport system, healthcare infrastructure, or simply the number of private vehicles on the roads. Henceforth, in exercising experience and observation, students should only focus on the object and the perceivable forms of the theme.

The act of reflection, taking place simultaneously with conceptualisation, is administered on the relationships between the object and the theme, rather than on either of the components themselves as is usually the habit. This is an importation of how traditional apprenticeship practices it. It is precisely through deliberating over how wood, furniture, hammering and chiselling relate to straight lines that penetrate the sky, the sea, the mountain and buildings, that a novice carpenter learns and expands his skills and toolkits in a self-directed creative manner, moving between the concrete object and the abstract theme and touching everything inbetween. Students in our courses are constantly reminded that their primary task is not only to experience and observe, but to produce novel conceptions of, for instance, the relationships between conservation practices and economic development. Are conservation practices necessarily compromised by the needs of economic development? Does economic development necessarily destroy natural and cultural heritage? Can conservation practices contribute to speedier economic development? Or do all societies necessarily distinguish between the economic domain from that of nature and culture? These are some of the questions that arise from a simple insertion of an object-theme pair into the experiential actions of experience and reflection.

But what of skills and objective? As much as the object-theme pair serves to scaffold students' experiential actions to be more focused, room for imagination and experimentation needs to be maintained. This latter goal is achieved through little mentions of the skills that students are expected to acquire, and the objectives of doing so. We surmise that there could be many techniques invented by students in their exploration of the object-theme relationships, that could very well better in analysing and transforming the object of the course than the ones that instructors had provided. The objective of doing so could also be re-invented, as students traverse between different objects, field sites, and contexts, witnessing how not only skills can be adapted, but also objectives of administering them. 

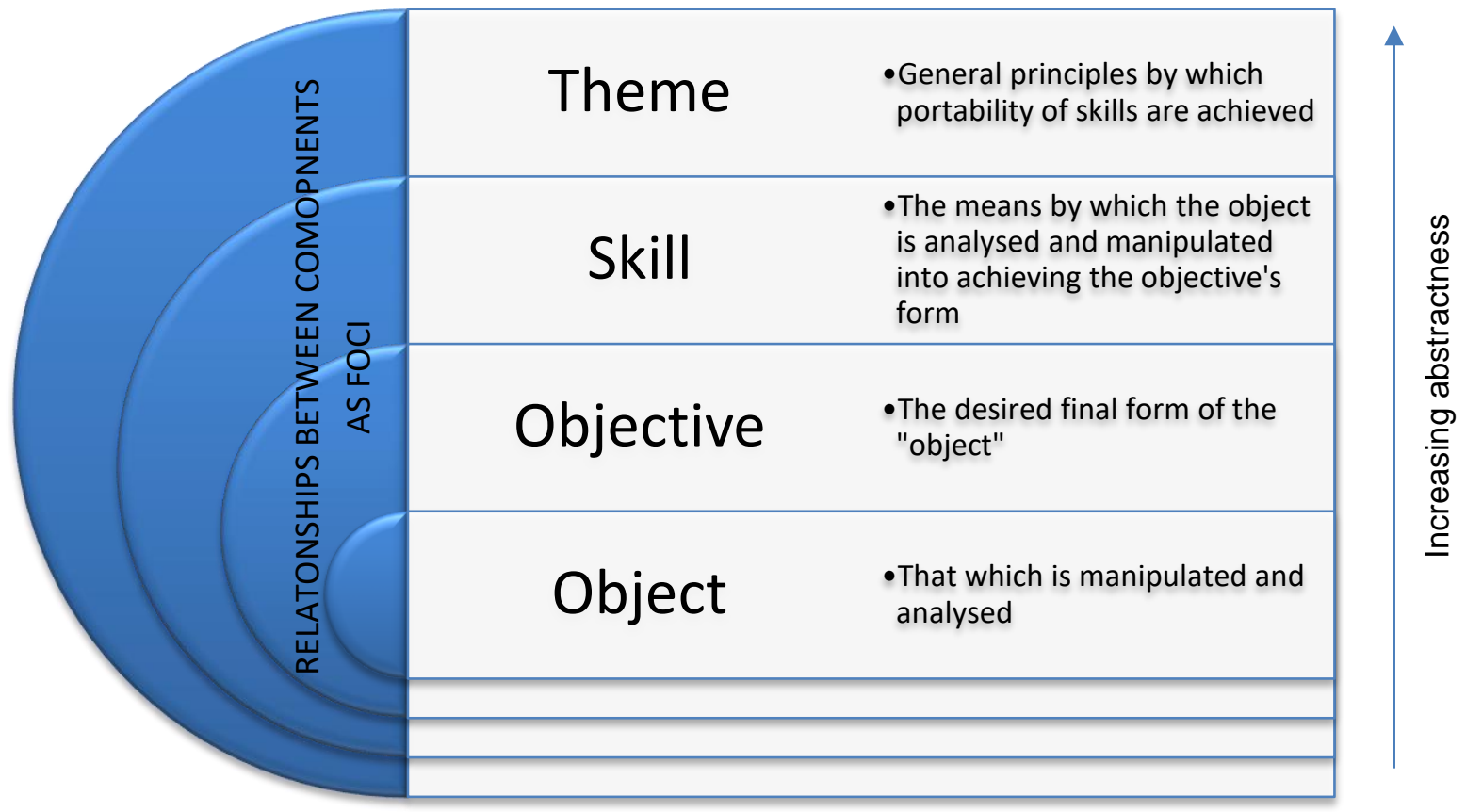

Figure 1: The components of traditional crafts, and their implementation into the ELCT. The unique feature of this framework is the focus on the relationships between the components rather than any one component itself, and the noveltisation of these relationships.

\section{COURSE DESIGN}

We run a series of courses commonly referred to as overseas study missions that involve a mix of e-learning, classroom seminars, and a field trip to a foreign city. This means that unlike conventional courses, we are required to provide material that students have to digest and be evaluated on even before meeting them, and develop a field-education plan to be executed with foreign partners. With the above-mentioned new experiential learning framework, our unique course design and execution could then be derived systematically in the following ways:

\subsection{Topics}

Topics of courses should remain relevant to the object, theme, and the relationships between them. They should include some background knowledge of the context within which the object-theme occurs, accounts of the object and the theme, and most importantly, the functions and purposes of the experiential learning framework. The relationships between the object and the theme should be touched upon lightly, to prevent students from merely regurgitating what the instructors have covered.

\subsection{Itinerary and Activities}

As mentioned briefly, the field trips should only involve sights, sounds, and smells that reveal the object and theme. Activities should be guided by the two experiential actions i.e.; they should allow students to experience and reflect on the object and theme (and their relationships) and how other practitioners interact with the object within the larger context of the destination.

\subsection{Learning Outcomes and Assignments}

Learning outcomes should reflect what students are expected to have learnt about the topics, revealing how students analyse and transform the object of the course, their understanding of the theme, and their abilities to develop refreshing takes on the relationships between the object and theme. Assignments should be designed to allow students to express the learning outcomes as authentically as possible.

\section{IMPLEMENTATION AND RESULTS}

We observed, from implementing our refreshed experiential learning framework, a series of transformation in students' performance compared to using classic ELCT in a wholesale manner. These transformations appear in the following areas: 
1. The profundity of questions asked

2. Metacognitive habits

3. Interest in the course

4. Willingness to be experimental

\subsection{Asking Questions}

In a course that involves a field trip to Taipei, Taiwan, two iterations of the course were compared. The first iteration was run prior to the invention of the said framework, and focuses broadly on "social work". The second adopted "civic altruism in Taiwan" as the object and "cultural relativity" as the theme, with components of the course derived accordingly. The instructor's intent behind this pair was to show students that ground-up initiatives are guided by certain ethical principles that vary across countries, that what is considered altruistic in one culture may be deemed detrimental in another.

The questions that students asked in the two iterations were stark in their level of profundity. In the first, the most common questions solicit concrete information about practical work-related matters, including, "how much are Taiwanese social workers paid?", "what are their career prospects?", "how many hours do they clock per week?", etc. Students made little to no attempt at reflecting or conceptualising what they have observed, or are remotely aware of the forces at work that shaped the social services, or the latter's impact on overcoming the class divide.

In the second iteration, the questions students asked included, "do social workers' ethical principles clash with that of their clients?", "do they consider their cultural tradition to be similar to that of other Chinese?", "are their altruistic intent viewed with suspicion by their government?", and "do you think this style of volunteerism would go down well in Singapore?" Questions like these and more show the full impact of having the phenomenon of "civic altruism" to attend to, the exercise of reflection on the relationships between civic altruism and cultural relativism, and attempting new ways of conceiving how these two could manifest in another society. Most importantly, the instructor feedback that many these questions were offered without much prompting; it shows that the experiential learning framework has functioned well as a self-help heuristic device without the need for too much intervention from the instructor.

\subsection{Metacognition}

Metacognition, simply put, refers to the act of "thinking about thinking" (Flavell, 1979); it involves the practice of deliberate awareness on one's thought processes and the assumptions behind them. Some themes in our series of courses describe structural forces that shape the object of the course, which led to some students reflecting on those very structural forces that shaped them, particularly their presumptions about the objects of the courses. This can be observed in a course with the object "women's empowerment in India" with the theme "gender equality". Many students, particularly the female ones, began to reflect on how gender inequality in Singapore has shaped their ways of thinking about a myriad of issues, including feminism, universal suffrage, the role of women in both domestic and public spheres, etc. They began to deconstruct assumptions about what they used to consider the "militant" nature of feminism, conduct research about how the Suffragettes' sacrifices gave them the power of the vote, and even how their lack of interest in STEM subjects were consequences of "hegemonic masculinity". This compares starkly to previous service-learning trips to the same location, after which students could only talk about the plights of Indian women, how they were commonly abused by men, and the ways in which they organise themselves to improve their lives.

\subsection{Interest}

Students in our institution are required to clear an overseas experience graduating requirement, and some of them consider this a chore. The implementation of our experiential learning framework appears to have changed some of their minds about the value of overseas study missions. Some students have remarked that the course contents prior to the implementation of this framework were often too fragmented, and assignment questions were also often irrelevant to what they were shown in the field. Common feedback about their overseas experience also included the lack of guidance on what they were supposed to learn about, what they were supposed to write in their reflection essays, and most of all, the pointlessness of going overseas when they could just watch a video on YouTube about the issues covered. Students who had taken courses under our new framework, in contrast, continued to show keen interest in the destination city even after the completion of the courses. Many of them pointed out that a clear articulation of what they were supposed to pay attention to in the field, and what they were supposed to reflect on in their assignments, helped them greatly appreciate what the foreign destination had to offer in expanding their awareness of how they feature within the larger scheme of things. 
To use an example, a course called "moving resources across the Silk Road" requires students to embark on treks across the Gobi Desert, and relate their journeys of "moving resources" across the terrain to the theme "the Chinese salvational narrative" found in Chinese folklore. In its previous as an adventure leadership course, students were lamenting that what they learned from the trip could be achieved without it being run as a creditbearing course, with assignments that had little to do with what they experienced trekking through the desert. The new iteration prepared them for the trip by first introducing them to the theme, present in the book Journey to the West and numerous folklores familiar to many of them. This matching of a seemingly mere physical experience with Chinese traditions piqued their interest; all the students in the course remarked that they never knew how the notion of "gaining immortality through suffering", a central cultural trope in Chinese religions, encapsulates the necessity of suffering in heeding a calling by tagging a spiritual dimension to it.

\subsection{Experimentation}

An overly-structured course curriculum or an overly-permissive one, we observed, often lead students regurgitate the course content or examples and interpretations provided by their instructors. In the former, because the curriculum has laid out clear boundaries of what they need to know, they find no encouragement to explore beyond those boundaries. In the latter, the lack of proper scaffolding caused so much uncertainty that they cling to the reference material provided in the course, and every word uttered by the instructor as the safest bet on getting good grades in the courses. Our framework explicitly encourages them to explore "relationships" rather than define "essences", specifically through assignments that ask them to come up with novel interpretations of the object-theme relation. We have also begun experimenting with assignments that require students to, instead of providing answers, ask questions that lead them to explore the object-theme relationships and justify why those are good questions (this would be discussed in another publication). The effect of these measures, compared to previous iterations of courses, saw an increase in the number of assignments that were more "daring" in offering hypotheses, possibilities, and even predictions.

A good example would be a course called "entrepreneurial spirit in Israel" with the theme "balagan", a Hebrew word that refers to a state of messiness/chaos. A previous iteration merely focused on entrepreneurship in Israel, with the intention of showing students the vibrant entrepreneurial scene in the country, and hopefully, encourage them to achieve the same for Singapore. The consequence was that students merely tried to replicate what the Israeli entrepreneurs were doing or figuring out how they did it, without any thought to the existential conditions that gave rise to their inclinations towards it. Students have commented that the inclusion of the theme and encouragement from instructors to explore how it relates to the object, made them more willing to explore more possible explanations for the Israelis' entrepreneurial spirit, particularly in relation to Israel's political situation, collective memories of their past, and most importantly, a stoic and constructive attitude towards chaos.

\section{SUMMARY}

This paper presents the use of a novel framework for experiential learning, derived from integrating core components of traditional craft apprenticeship and David Kolb's experiential learning cycle theory. Through the use of these core components, distilled into a conceptual pair, as the objects for the experiential actions of experience and reflection, we created an experiential learning framework that works under the constraints of a university setting. Comparison of our overseas study mission courses before and after the implementation of the framework shows marked improvements students' abilities to ask profound questions, their metacognitive habits, their level of interest in overseas missions, and their willingness to experiment.

\section{REFERENCE LIST}

Bradberry, L., \& De Maio, J. (2018). Learning By Doing: The Long-Term Impact of Experiential Learning Programs on Student Success. Journal Of Political Science Education, 15(1), 94-111. doi: 10.1080/15512169.2018.1485571

Dilley, R. (1989). Secrets and Skills: Apprenticeship among Tukolor Weavers. In M.W. Coy (ed.) Apprenticeship: From Theory to Method and Back Again, pp. 181-198. New York: SUNY Press.

Kolb, D. A. (2015). Experiential learning. Upper Saddle River, New Jersey: Pearson Education.

Kolb, D. A. (1976). Learning Style Inventory. Boston, Massachusetts: McBer. 
Kolb, D. A. (1984). Experience as the source of learning and development. In D. A. Kolb, Experiential Learning (p. 41). Englewood Cliffs, NJ: Prentice-Hall Inc.

Entwistle, N. (1997). Contrasting perspectives on learning. In F. Marton, D. Hounsell, \& W. J. Entwistle (Eds.), The Experience of learning. Implications for Teaching and Studying in Higher Education, Second Ed. (pp. 3-22). Edinburgh: Scottish Academic Press.

Esther N. Goody (1982). From Craft to Industry: The Ethnography of Proto-Industrial Cloth Production. Cambridge Papers in Social Anthropology. New York: Cambridge University Press.

Field, J. \& Dubhchair, M.O. (2001). Recreating Apprenticeship: Lessons from the Irish standards-based model, Journal of Vocational Education and Training, 53, pp. 247-261.

Flavell, J.H. (1979). "Metacognition and cognitive monitoring. A new area of cognitive-development inquiry". American Psychologist. 34 (10): 906-911

Fuller, A. \& Unwin, L. (2001). From Cordwainers to Customer Service: The changing relationship between apprentices, employers and communities in England. Skills, Knowledge and Organisational Performance (SKOPE) Monograph No. 3, Oxford and Warwick Universities.

Gow, L., \& Kember, D. (1993). Conceptions of teaching and their relationship to student learning. British Journal of Educational Psychology, 63, 20-33.

Hayden, M., Mclntosh, S. (2018). International education: the transformative potential of experiential learning, Oxford Review of Education, 44:4, 403-413

Kolb, A. Y., \& Kolb, D. A. (2006). Learning styles and learning spaces: a review of the multidisciplinary application of experiential learning theory in higher education. In R. S. Sims (Ed.), Learning styles and learning: a key to meeting the accountability demands in education (pp. 45-91). Hauppauge, NY: Novus Publishers.

Kolb, D. A. (1981). Learning styles and disciplinary differences. In A. W. Chickering (Ed.), The Modern American College (pp. 232-255). San Francisco, LA: Jossey-Bass.

Lancy, David F. (2012). "First You Must Master Pain": The Nature and Purpose of Apprenticeship. Anthropology of Work Review, Volume XXXIII, Number 2, pp.113-126.

Lave, J. \& Wenger, E. (1991). Situated Learning. Cambridge: Cambridge Press.

Loveless, B. (2021). Understanding the Benefits of Experiential Learning for Executive Leader Development: A Mixed Methods Approach. Dissertations. $205 \mathrm{https} / / /$ digital.sandiego.edu/dissertations/205

Marton, F., \& Saljo, R. (1997). Approaches to learning. In F. Marton, D. Hounsell, \& W. J. Entwistle (Eds.), The Experience of Learning. Implications for Teaching and Studying in Higher Education. Second Ed. (pp. 39-58). Edinburgh: Scottish Academic Press.

Millroy, Wendy L. (1992). An Ethnographic Study of the Mathematical Ideas of a Group of Carpenters. Journal for Research in Mathematics Education. Monograph, Vol. 5. pp. +ix-x+1-210

Newstead, S. E., \& Hoskins, S. (2003). Encouraging student learning. In A Handbook of Teaching and Learning in Higher Education. Enhancing Academic Practice, second ed. London: Kogan Page.

Passarelli M. A., \& Kolb, D. A. (2012). Using Experiential Learning Theory to Promote Student Learning and Development in Programs of Education Abroad. In Student Learning Abroad. Sterling, VA.

Spencer, J. A., \& Jordan, R. K. (1999). Learner centered approaches in medical education. BMJ, 318, 12803. doi:doi.org/10.1136/bmj.318.7193.1280

Walkin, L. (2000). Teaching and Learning in Further Adult Education. Cheltenham: Stanley Thomes Publishers Ltd.

Yballe, L., \& O'Conner, D. (2000). Appreciative pedagogy: constructing positive models for learning. Journal of Management Education, 24(4), 474-83. 